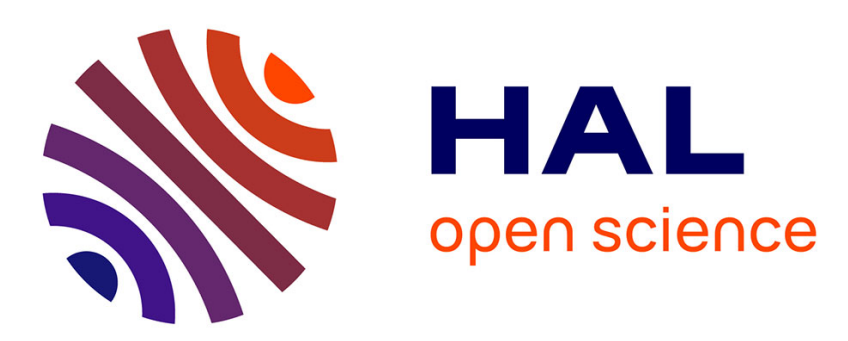

\title{
Evaluation of Systems Contractor's Ability to Deliver a Solution to Offer During an Engineer-To-Order Bidding Process
}

\author{
Abdourahim Sylla, Élise Vareilles, Thierry Coudert, Michel Aldanondo, \\ Laurent Geneste
}

\section{To cite this version:}

Abdourahim Sylla, Élise Vareilles, Thierry Coudert, Michel Aldanondo, Laurent Geneste. Evaluation of Systems Contractor's Ability to Deliver a Solution to Offer During an Engineer-To-Order Bidding Process. INSIGHT - International Council on Systems Engineering (INCOSE), 2019, 22 (4), pp.40-42. 10.1002/inst.12275 . hal-02443625

\section{HAL Id: hal-02443625 \\ https://imt-mines-albi.hal.science/hal-02443625}

Submitted on 25 Feb 2020

HAL is a multi-disciplinary open access archive for the deposit and dissemination of scientific research documents, whether they are published or not. The documents may come from teaching and research institutions in France or abroad, or from public or private research centers.
L'archive ouverte pluridisciplinaire HAL, est destinée au dépôt et à la diffusion de documents scientifiques de niveau recherche, publiés ou non, émanant des établissements d'enseignement et de recherche français ou étrangers, des laboratoires publics ou privés. 


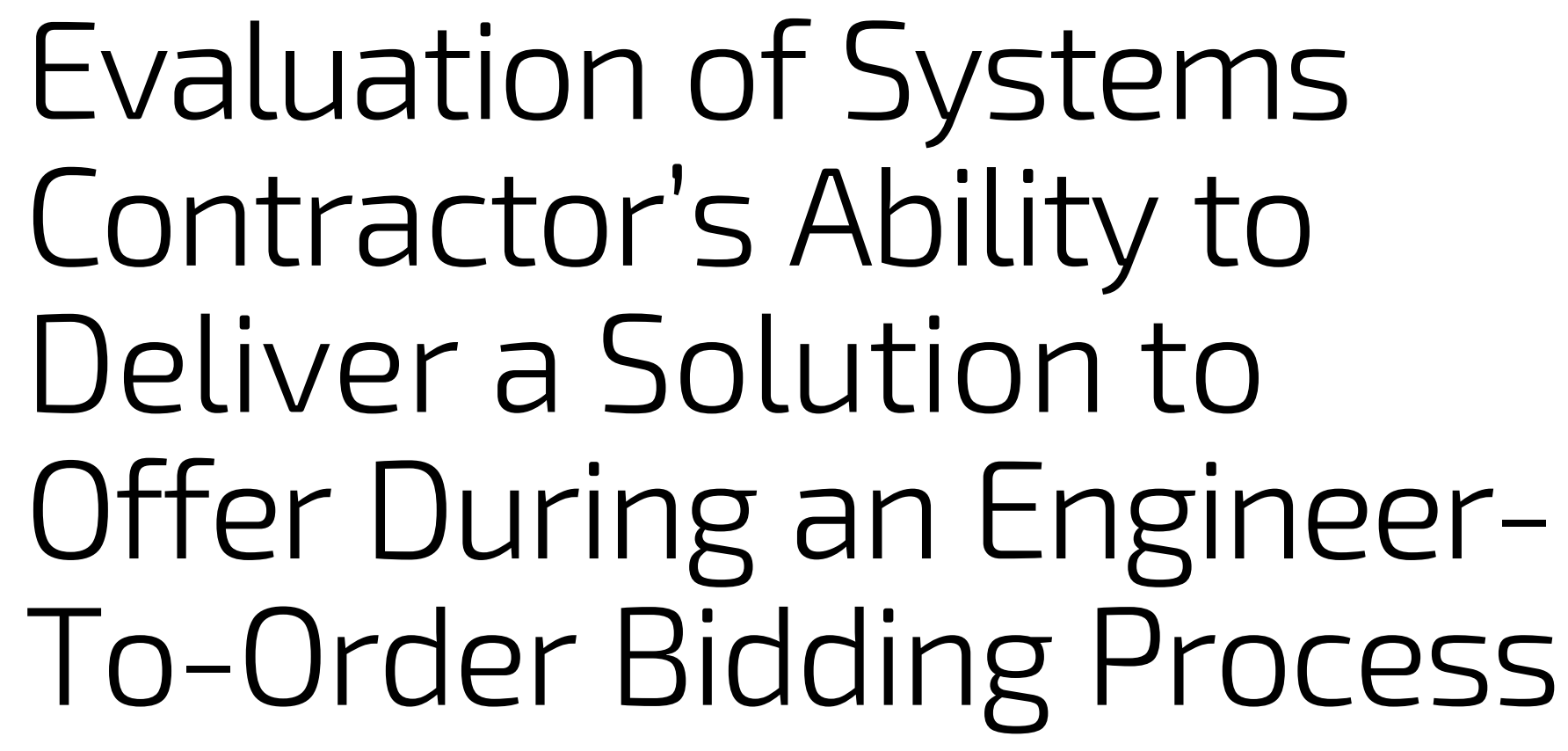

Abdourahim Sylla, abdourahim.sylla@enit.fr; Elise Vareilles, elise.vareilles@mines-albi.fr; Thierry Coudert, thierry.coudert@enit.fr; Michel Aldanondo, michel.aldanondo@mines-albi.fr; and Laurent Geneste, laurent.geneste@enit.fr

\section{ABSTRACT}

To increase their business volume and remain competitive, systems contractors must propose competitive and feasible solutions to customers. However, Engineer-To-Order industrial situations become challenged by the lack of relevant information. This article, to help companies to overcome this problem, presents two confidence indicators, their evaluation methods, and a way to use them during a design process. These indicators allow evaluating a company's future ability to offer a solution during a bidding process.

\section{INTRODUCTION}

$\mathrm{n}$ the bidding process context, to transmit a commercial offer to a customer, a systems contractor (or a bidder) must design a technical bid solution which complies with the customer's requirements. In general, the technical bid solution contains two interconnected parts (see Figure 1). The first part is the technical system (TS) which corresponds to the customer's technical and functional requirements and includes sub-systems (SS) which the system architecture helps integrate (Sauser, Ramirez-Marquez, Henry, and Dimarzio 2008). The second part is the technical system's delivery process (DP) which incorporates activities and resources (ACT) necessary to develop, assemble (or manufacture), and deliver the technical system once the customer accepts the offer. Offers include only the technical system solutions. However, it is crucial to design and evaluate both parts to perform a realistic solution evaluation, especially their cost, delivery date, and feasibility (or associated risks).

In an Engineer-To-Order (ETO) bidding process, the customer's requirements
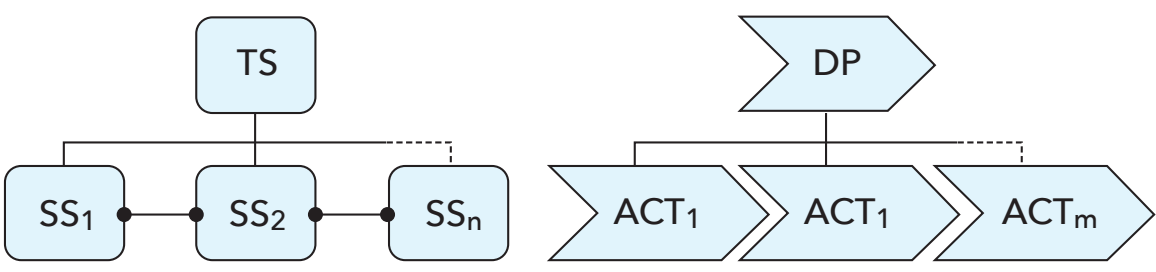

Figure 1. Technical bid solution

exceed the range of available technical bid solutions within the supplier company. Hence, to propose a relevant offer, it is necessary to design a solution which covers all the customer's requirements (Zheng Xu, Yu, and Liu 2017). However, in general, customers allow limited time to submit an offer. In addition, as customers cannot guarantee the offer's acceptance, optimizing resources and time during the bidding process is crucial when customers do not accept the offers (Kromker 1998). Consequently, at the bidding phase, several companies perform a pre-design of the potential solutions instead of a detailed design reducing the resources and time used during offer elaboration. However, these partially designed solutions contain uncertainty and risks regarding the companies' future abilities to develop and deliver the proposed solutions after the customers accept their offers (Chapman, Ward, and Bennell 2000)(Sylla, Vareilles, Coudert, Kirytopoulos, Aldanondo, and Geneste 2017). In some companies, experienced designers provide subjective judgments to estimate the company's ability to deliver a solution. These judgments, human dependent, lead to inaccurate or inexact estimations and result in cost growth and schedule slippage during solution realization and delivery. This article focuses on evaluating a company's ability to develop and deliver a solution offered during a bidding process. The ability acts as a measure of the risks associated with a specific offer (a technical 
system and delivery process pair). Thus, its assessment enables bidders to anticipate risks related to the technical system's development and delivery after the customer accepts the offer. Therefore, this article assists the risks management process, as defined in the ISO/IEC/IEEE 15288:2015 standards, by presenting two confidence indicators, their evaluation methods, and how to use them during a design process. Overall Confidence in System (OCS) is the technical system indicator and Overall Confidence in Process (OCP) is the delivery process indicator. Our previous work (Sylla, Vareilles, Coudert, Kirytopoulos, Aldanondo, and Geneste 2017) proposes both indicators and allows bidders to assess their ability to deliver a solution offered during a bidding process.

\section{THE CONFIDENCE INDICATORS AND THEIR EVALUATION METHOD}

In the proposed method, two different indicators characterize each technical bid solution part (technical system and delivery process). The first indicator is factual and intrinsic to the elements (sub-systems, sub-system integrations, and activities) which compose the technical bid solution. They provide an objective evaluation of the technical system's maturity and the delivery process' feasibility. The second indicator, based on the designer's subjective feeling, allows considering the designer's expert feeling about the solution's success.

As shown in Figure 2, to compute the technical OCS, the factual indicators Technology Readiness Level $\left(\mathrm{TRL}_{\mathrm{i}}\right)$ and Integration Readiness Level $\left(\mathrm{IRL}_{\mathrm{ij}}\right)$ characterize each sub-system and each sub-system integration ( $i$ and $j$ ). The TRL and IRL indicators assess the sub-systems and their integrations developmental maturity (Mankins 1995) (Sauser, Ramirez-Marquez, Henry, and Dimarzio 2008) and measure on a nine-level scale. The subjective indicators Confidence In Sub-system (CIS ${ }_{\mathrm{i}}$ ) and Confidence In the integration of Sub-systems $i$ and $j\left(\right.$ CIS $\left._{i j}\right)$ further characterize each sub-system (i) and each sub-system integration ( $i$ and $j$ ). They assess the designer's expert feeling about the sub-systems and their integrations success and measure on a five-level scale. Then, an aggregation method (Sauser, Ramirez-Marquez, Henry, and Dimarzio 2008) computes the technical system's factual and subjective (System Readiness Level (SRL) and the Confidence In System (CIS)). SRL and CIS indicators measure on a five-level scale. Finally, a method computes the technical system's OCS using the SRL and CIS indicators (see Figure 2), measured on a nine-level scale.

To compute the delivery process' overall confidence (OCP), the factual indicator

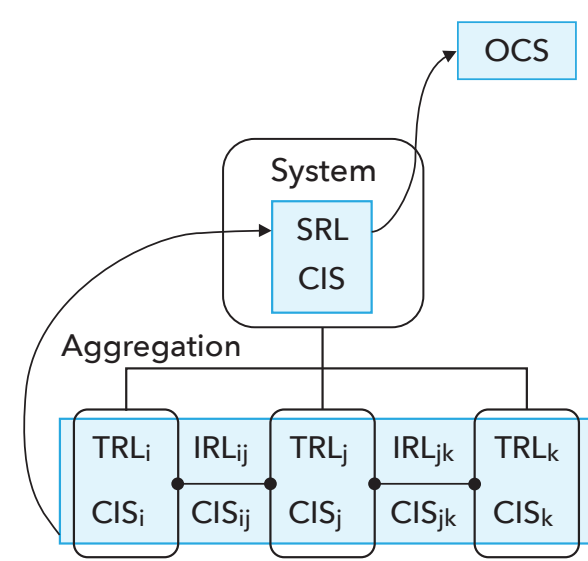

Sub-systems and integration

Figure 2. OCS and OCP indicators

Activity Feasibility Level $\left(\mathrm{AFL}_{1}\right)$ characterizes each activity 1 (see Figure 2). The AFL indicator measures the activities' feasibility by aggregating three dimensions: (i) the resource competence, (ii) the resource availability, and (iii) the activity risk. AFL measures on a five-level scale. The subjective indicator Confidence In $a$ delivery Process activity $\left(\mathrm{CIP}_{\mathrm{k}}\right)$ further characterizes each activity. It assesses the designer's expert feeling about the activity's success and measures on a five-level scale. Then, a weighted average aggregation method computes the two delivery process indicators (Process Feasibility Level (PFL) and Confidence In Process (CIP)). PFL and CIP indicators measure on a five-level scale. The same method used to compute the technical system's OCS computes the delivery process' OCP based on the PFL and CIP indicators (see Figure 3). The OCP indicator measures on a nine-level scale.

With these two confidence indicators (OCS and OCP), a bidder will have a powerful tool that can propose an attractive and feasible solution to a customer during a bidding process. A bidding process' or engineering design process' design phase obtains several potential solutions (Renzi, Leali, and Di Angelo 2017). In this situation, the most critical task in a bidding process is selecting the most interesting solution to offer while maintain-

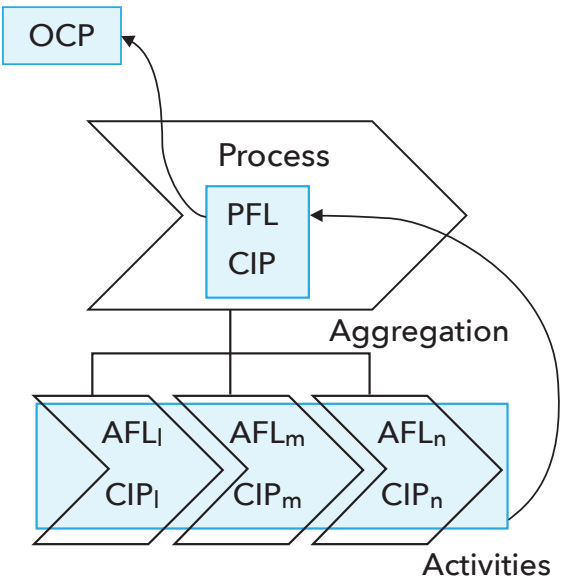

ing feasibility and realism. The solutions attractiveness relies on the evaluation criteria values such as cost, delivery date, and technical performances. Its feasibility relies on the company's future ability to develop and deliver it according to the expectations. This feasibility can consider the confidence indicators presented in the previous section. Thus, a good solution has good values for both the evaluation criteria and the confidence indicators. Therefore, in addition to the standard criteria (cost, delivery date, and technical performances), the two confidence indicators (OCS and OCP) can act as decision criteria in a design process to select the most interesting design solution. Following is an example of confidence indicator use.

We assume a configuration software designs and evaluates the potential solutions (Sylla, Guillon, Vareilles, Aldanondo, Coudert, and Geneste 2018). A configuration software is a knowledge-based design tool based on a generic model. A generic model contains relevant knowledge characterizing the technical bid solution diversity offered by a supplier company. This generic model associated with a relevant decision aiding tool allows the designer to instantiate relevant solutions according to the

\section{THE USE OF THE CONFIDENCE INDICATORS IN A DESIGN PROCESS}

\begin{tabular}{|c|c|c|c|c|c|c|}
\hline \multirow{2}{*}{\multicolumn{2}{|c|}{ OCS/OCP }} & \multicolumn{5}{|c|}{ CIS/CIP } \\
\hline & & \multirow{2}{*}{$\begin{array}{c}\text { level } 1 \\
1\end{array}$} & \multirow{2}{*}{$\begin{array}{c}\text { level } 2 \\
2\end{array}$} & \multirow{2}{*}{$\frac{\text { level } 3}{3}$} & \multirow{2}{*}{ level 4} & \multirow{2}{*}{ level 5} \\
\hline \multirow{5}{*}{$\sum_{\frac{1}{n}}^{\frac{1}{n}}$} & level 1 & & & & & \\
\hline & level 2 & 2 & 3 & 4 & 5 & 6 \\
\hline & level 3 & 3 & 4 & 5 & 6 & 7 \\
\hline & level 4 & 4 & 5 & 6 & 7 & 8 \\
\hline & level 5 & 5 & 6 & 7 & 8 & 9 \\
\hline
\end{tabular}

Figure 3. OCS and OCP computation matrix 


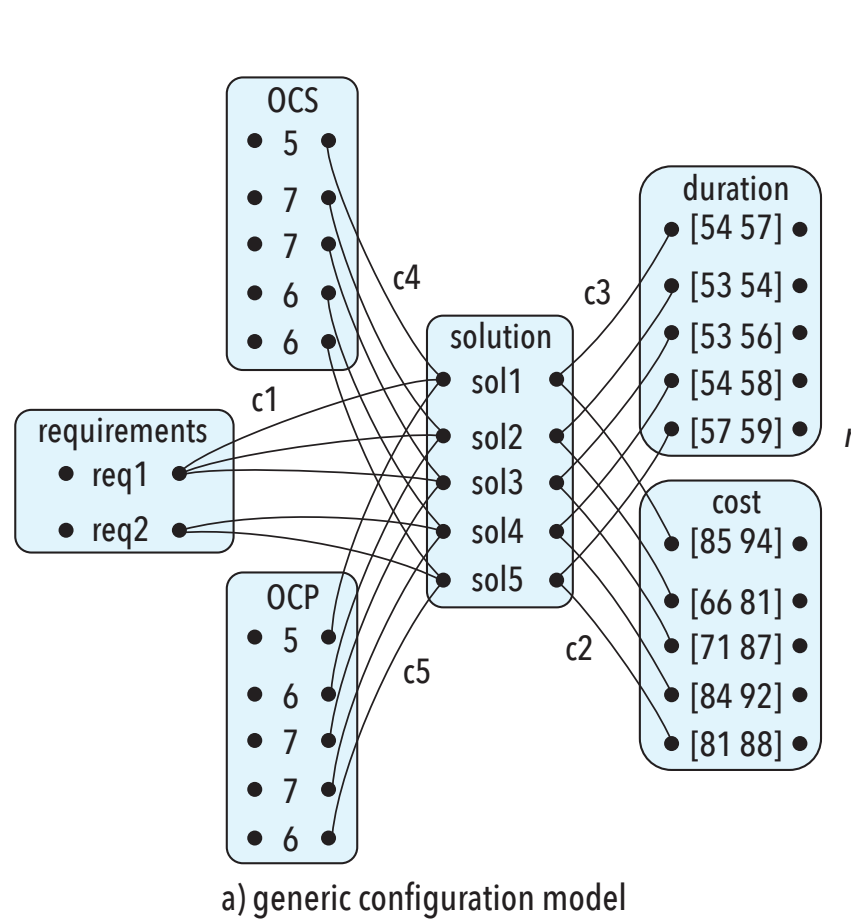

a) generic configuration model

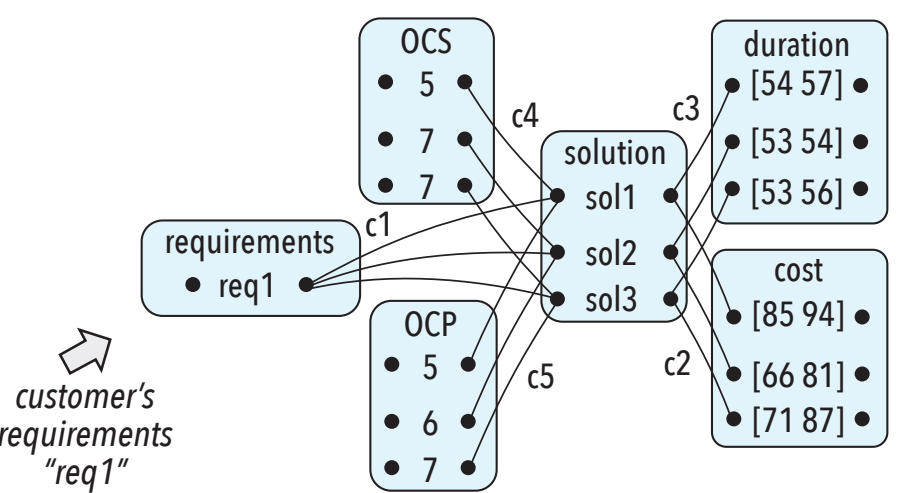

b) the relevant solutions to the requirements "req1"
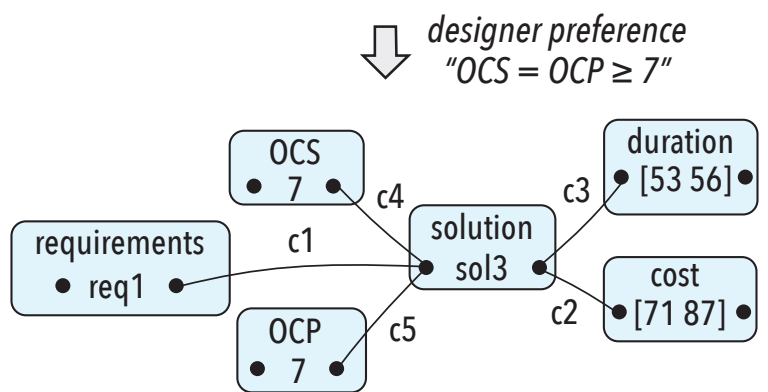

c) the relevant solution to the designer preferences

Figure 4. An example of confidence indicator use

customer's requirements.

Consider the simple generic configuration model presented Figure 4, developed using a Constraint Satisfaction Problem (CSP) framework. A CSP framework's configuration problem model uses three elements: (i) a variable set, (ii) a finite domain for each variable, and (iii) constraints linking the variables. In this model, the requirements, the solution, the cost, the duration, and each confidence indicator (OCS and OCS) associates to a variable. Their possible values represent the corresponding variable's domain. Therefore, technical bid solutions link to the variable "solution." Five possible solutions ("sol1" to "sol5") represent this variable's domain. Constraint " $c 1$ " defines the solutions relevant to specific customer's requirements (sol1, sol2 and sol3 are relevant to the requirements "req1"). Constraints " 2 " and "c3" define each solution's cost and duration whereas constraints " $\mathrm{c} 4$ " and "c5" define each solution's OCS and OCP. For instance, for the technical bid solution "sol3": duration $=[5356]$, cost $=$ [71 87], OCS $=$ OCP $=7$.

Considering a design or a configuration problem as a CSP allows constraint filtering mechanisms to act as an aiding tool. Each customer's requirement or designer's preference triggers constraints to propagate this decision and prune variable values for the solutions, cost, and duration while automatically updating the confidence indicators (Aldanondo and Vareilles 2008). As an example, consider the customer's requirements correspond to "req1." Then, only the three solutions "sol1," "sol2," and "sol3" are relevant (see Figure 4). Now, the designer must select one solution to propose to the customer. To consider the company's future ability to deliver the solutions, the designer can define required OCS and OCP values for selecting a solution. Let us consider the designer has selected " 7 " as the required OCS and OCP values. Then, only the solution "Sol3" corresponds to the designer preference (see Figure 4). Consequently, the commercial offer considers this solution "sol3." Note in a more practical or complex case, one could optimize several criteria (cost, OCS, and OCP). In such a situation, a multicriteria decision support approach could determine each criterion's appropriate weight and select the most interesting solution (Zheng, $\mathrm{Xu}, \mathrm{Yu}$, and Liu 2017).

\section{CONCLUSION}

We have presented two confidence indicators (OCS and OCP) and their evaluation method for evaluating a company's ability to develop and deliver a solution offered during an Engineer-To-Order bidding process. Two different metrics (factual and subjective) characterize the OCS and OCP indicators. We have also shown how to use them as a decision criterion to select a feasible solution in an engineering design process. This represents a first step in the validation process of the proposed indicators and their evaluation method. However, proving their applicability and effectiveness requires performing a more realistic case study, considered as future research. Future research should also consider developing a method for a more factual evaluation of the subjective indicators CIS and CIP. -

\section{REFERENCES}

- Aldanondo, M., and É. Vareilles. 2008. "Configuration for Mass Customization: How to Extend Product Configuration towards Requirements and Process Configuration." Journal of Intelligent Manufacturing 19(5): 521-35. doi:10.1007/s10845-008-0135-z.

- Chapman, C.B., S.C. Ward, and J.A. Bennell. 2000. "Incorporating Uncertainty in Competitive Bidding." International Journal of Project Management 18(5): 337-47. doi:10.1016/ S0263-7863(00)00013-2.

- Kromker, M. 1998. "BIDPREP-towards Simultaneous Bid Preparation.” International Journal of Computer Integrated Manufacturing 11(1): 45-51. doi:10.1080/095119298130967.

- Mankins, J.C. 1995. “Technology Rediness Levels.” White paper, NASA Advanced Concepts Office.

- Renzi, C., F Leali, and L. Di Angelo.. 2017. "A Review on Decision-Making Methods in Engineering Design for the Automotive Industry." Journal of Engineering Design 28(2): 118-43. doi:10. 1080/09544828.2016.1274720. 